Article

\title{
On the Predictability of Radiation Fog Formation in a Mesoscale Model: A Case Study in Heterogeneous Terrain
}

\author{
Thierry Bergot 1 and Renaud Lestringant * \\ Centre National de Recherche Météorologique, Université de Toulouse, Météo France, CNRS, F-31057 Toulouse, \\ France; thierry.bergot@meteo.fr \\ * Correspondence: renaud.Lestringant@meteo.fr
}

Received: 24 January 2019; Accepted: 7 March 2019; Published: 28 March 2019

check for updates

\begin{abstract}
This study evaluates the predictability of the formation phase of a radiation fog event observed during the night of 31 October 2015 to 01 November 2015 in the north-east of France at three sites managed by OPE (Observatoire Pérenne de l'Environnement). The fog layer shows significantly different behaviors at the three areas, which are located only a few kilometers apart. Three fog life cycles were observed: the formation of a dense adiabatic fog, the formation of a thin patchy fog, or no fog formation despite favorable conditions. This event was studied with the Meso-NH numerical mesoscale model at two horizontal resolutions, $500 \mathrm{~m}$ and $50 \mathrm{~m}$. Simulations at $50 \mathrm{~m}$ allow estimation of the spread of the predicted parameters over the heterogeneous terrain studied. These numerical simulations strongly suggest that this event involved numerous interactions and complex circulations. The wind above the nocturnal boundary layer greatly affects the transition of shallow patchy fog into thick adiabatic fog. These numerical simulations also show that the occurrence and type of fog could be very different over a small but heterogeneous area. It is also interesting to note that the spread of the simulated parameters was very high during the transition from shallow fog to a deep fog layer. The spread was concentrated during the regime transition between the fog formation and its maturity. This appeared to be the result of the complex interplay of processes at numerous ranges of scale. A new concept called "pseudo-process diagram" is presented. These pseudo-process diagrams are very good tools to analyze fog, and allow a good illustration of the spread of fog during this chaotic phase. This kind of concept seems a promising tool to analyze fog predictability in depth.
\end{abstract}

Keywords: fog; numerical mesoscale modelling; predictability

\section{Introduction}

Fog is known to have a strong societal impact while simultaneously being difficult to predict due to numerical non-linear interactions between physical and dynamical processes. Fog is characterized by small water droplets suspended in the near-surface atmosphere, reducing visibility to below $1 \mathrm{~km}$. With the expansion of air transport, the current cost of fog events is increasing. This triggers an increasing demand for accurate fog forecasts that could mitigate the societal impact of fog, for example by allowing appropriate preparations to be made at airport areas.

Unfortunately, despite all improvements made in the horizontal and vertical resolutions and the detailed physics of numerical weather prediction (NWP) models, predicting fog remains a challenge. In particular, the lack of accurate visibility forecasts is the result of a whole set of factors, including small-scale processes (e.g., Bergot et al., 2015 [1]), complex mesoscale circulation (e.g., Price et al., 2018 [2]), or microphysical processes (e.g., Boutle et al. 2018 [3]) among many others.

Many attempts to improve our knowledge of radiation fog have been made since the 1970 s. Several comprehensive observational programs including in situ measurements have been carried out, 
e.g., Roach et al. (1976) [4] at Cardington-UK, Meyer and Lala (1986) [5] at Albany-US, Guedalia and Bergot (1994) [6] at Lille-France, Duynkerke (1999) [7] at Cabauw-Netherlands, Fuzzi et al. (1998) [8] in the Po valley-Italy, Haeffelin et al. (2010) [9] in Paris-France, Pu et al. (2016) [10] MATHERHORN project at Utah-US over mountain terrain and more recently, Price et al. (2018) [2] with the 3D field experiment LANFEX over the UK. The main processes leading to fog formation are now well-known: cooling due to radiation, turbulence and land-atmosphere interactions (e.g., Bergot et al., 2007 [11], Terradelas and Bergot 2007 [12], Roman-Cascon et al., 2016 [13]). However, fog formation involves a myriad of interactions between physical processes, resulting in a subtle balance that allows fog formation while generating fog variability in time and space. Steeneveld and De Bode (2018) [14] demonstrated that the most influential parameters governing fog formation were soil conductivity and turbulent boundary-layer mixing, corroborating results from previous studies. They also pointed out that errors in one process could easily be hidden by errors or uncertainties in another. Moreover, the dominant process may change during the fog life cycle, making things even more complex.

The present study focuses specifically on the formation phase of radiation fog, as it is a challenging type of forecast. The formation phase of fog and the transition between shallow patchy fog and deep adiabatic fog are not clearly understood at present. Uncertainties remain about the evolution of shallow fog layer to the mature adiabatic phase. For example, the impact of local versus non-local effects is not really understood (Price et al., 2018 [2]). The impact of microphysics is also not fully clear. On the one hand, Steeneveld and De Bode (2018) [14] or Maronga and Bosveld (2017) [15] found that the choice of the microphysical scheme had relatively little influence during the formation phase, while, on the other hand, Boutle et al. (2018) [3] found that the microphysical parameters (e.g., droplet density) could accelerate the transition from thin patchy fog to deep adiabatic fog.

This study focuses on the fog onset and the initial development of the fog layer. Its key objective is to better understand the apparently chaotic transition between the formation phase and the mature phase of fog. By better understanding this transition, one can hope to better understand the physical processes driving the fog life cycle. However, the key objectives of this work is not to improve our knowledge of the physical processes. In the same way, the visibility calculation (e.g., Gultepe el al., 2006 [16]) is out of the goal of this article. Pseudo-process diagrams (coming from the paradigm of Steeneveld and De Bode, 2018 [14]) associated with high resolution simulations are used to try to illustrate the chaotic nature of fog during the formation phase.

The paper is organized as follows. Section 2 provides background on the numerical model and data used for this study. Section 3 focuses on the results of the numerical mesoscale simulations. A new paradigm based on the so-called pseudo-process diagram is presented in Section 4 to study the predictability of fog event. Conclusions are drawn and perspectives evoked in Section 5.

\section{Experimental Setup}

\subsection{Description of the Case Study}

The area studied is in the north-eastern region of France (see Figure 1). It is a very rural region with low population density $\left(<10\right.$ persons per $\left.\mathrm{km}^{2}\right)$. About $75 \%$ of the surface is used for agricultural production (mainly cereal crops and root crops). This region is characterized by small hills (about $100 \mathrm{~m}$ high) organized in a rather complex way.

Three observation sites (described below) are available over an area of about $20 \mathrm{~km} \times 50 \mathrm{~km}$. Firstly, a Météo-France meteorological station is located near Nancy $\left(48.58^{\circ} \mathrm{N} / 5.96^{\circ} \mathrm{E}\right)$. Temperature at $2 \mathrm{~m}$, humidity at $2 \mathrm{~m}$, wind at $10 \mathrm{~m}$ and visibility at $2 \mathrm{~m}$ are available every hour.

Secondly, the Montiers sampling area, called OPE (Observatoire Pérenne de l'Environnement), is composed of two main observation sites (see http:/ / www.nancy.inra.fr/en/Outils-et-Ressources/ montiers-ecosystem-research) a few kilometers apart. One OPE site is located in a beech forest approximately 50 years old $\left(48.53^{\circ} \mathrm{N} / 5.31^{\circ} \mathrm{E}\right)$, while the other OPE site is located in an agricultural area, mainly characterized by bare soil in winter $\left(48.51^{\circ} \mathrm{N} / 5.21^{\circ} \mathrm{E}\right)$. This last site is mainly used to 
describe the meteorological situation and to compare model results with observations. Wind at $5 \mathrm{~m}$ and $10 \mathrm{~m}$, temperature at $1 \mathrm{~m}$ and $3 \mathrm{~m}$, humidity at $1 \mathrm{~m}$ and $3 \mathrm{~m}$ and radiative fluxes at ground level are available every $30 \mathrm{~min}$.

Finally, the so-called Houdel sampling site $\left(48.56^{\circ} \mathrm{N} / 5.51^{\circ}\right.$ E) is located near the city of Houdelaincourt (https://www.andra.fr/latmosphere-sous-surveillance-houdelaincourt). It is composed of a $110 \mathrm{~m}$ high mast, providing measurements of temperature, humidity at $2 \mathrm{~m}$ and $50 \mathrm{~m}$, and wind measurements at $10 \mathrm{~m}$ and $50 \mathrm{~m}$. Visibility is only measured at $10 \mathrm{~m}$. Consequently, it is not possible to accurately determine the fog onset time at ground level for this site. Measurements are available every minute.
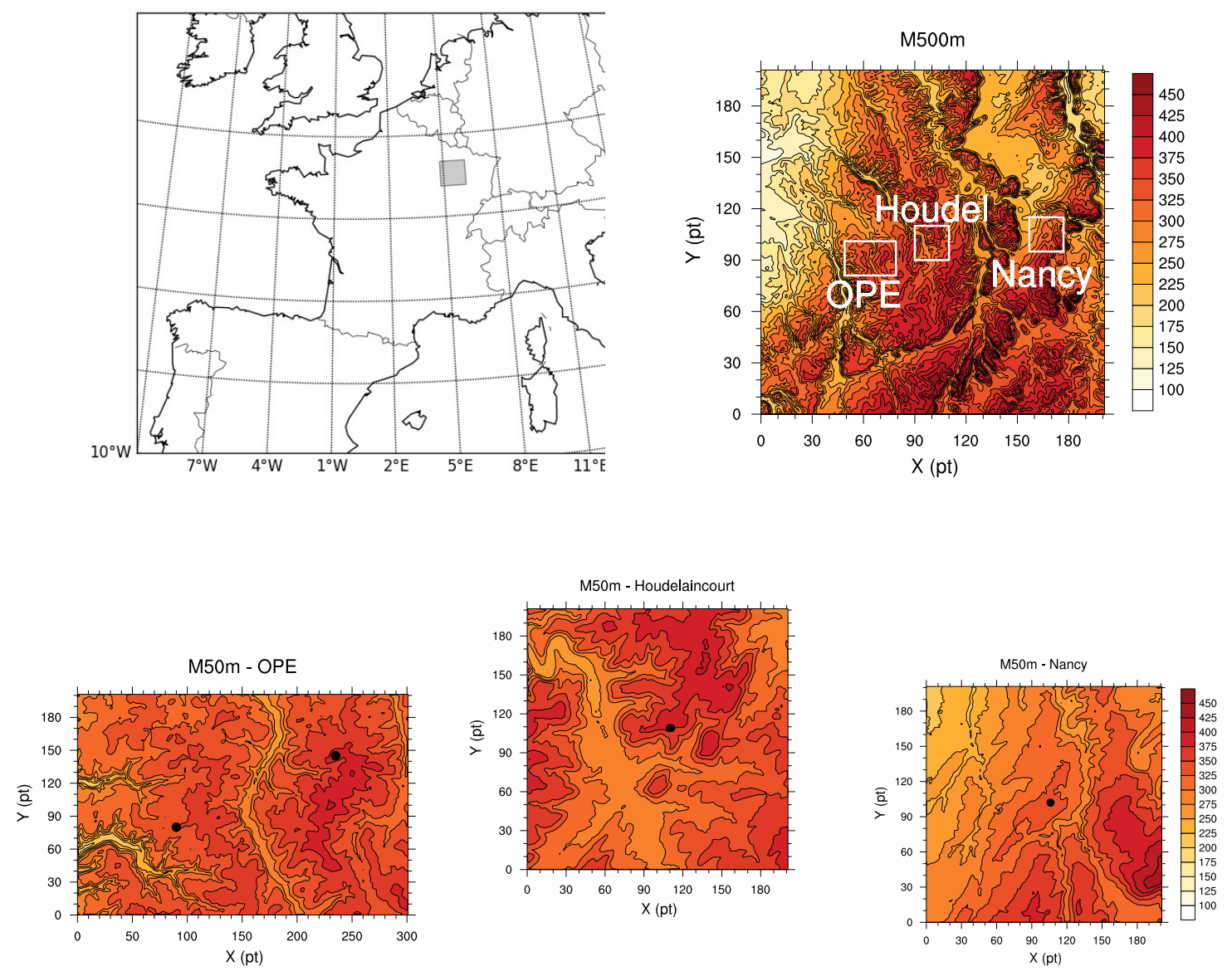

Figure 1. Geographical location of the simulation domains. The grey area corresponds to the M500m model. Topographical feature of the M500m and three M50m models, elevation in meters; the black dots correspond to the locations of observations.

The fog event under study occurred in the night of 31 October 2015 to 01 November 2015. Following Tardif and Rasmussen (2007) [17], it can be classified as an advection-radiation fog. The visibility during the afternoon was around $5 \mathrm{~km}$. At Nancy, it decreased rapidly at sunset, with values between $1 \mathrm{~km}$ and $3 \mathrm{~km}$. Dense fog first appeared at Nancy at about 2100 UTC (Figure 2). At Houdel, patchy fog appeared in the beginning of the night but it did not develop vertically. A transient fog reached $10 \mathrm{~m}$ between 0130 UTC and 0230 UTC (Figure 2). Dense fog was noted temporally but did not evolve into a deep adiabatic fog layer and did not reach the mature phase. At OPE, humidity was close to $100 \%$ during the night but no abrupt changes in net radiation were observed (not shown), suggesting that no dense fog layer was developed over OPE sites. Unfortunately, visibility observations are not available at the OPE. 


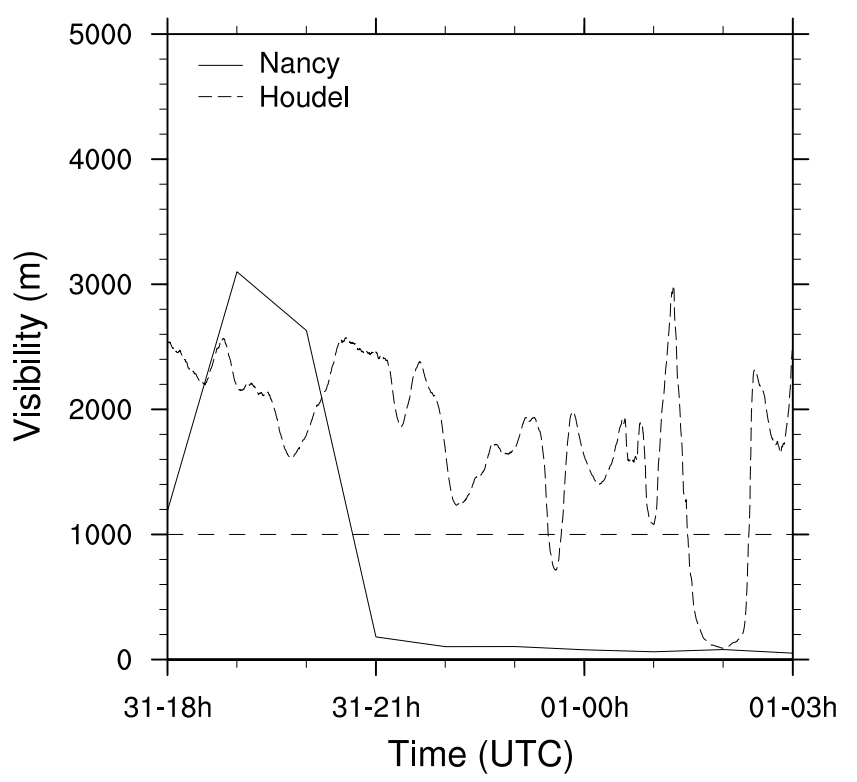

Figure 2. Visibility observed at $2 \mathrm{~m}$ at Nancy (solid line) and at $10 \mathrm{~m}$ at Houdel (dashed line).

The observed evolution of temperature and wind speed for the three observation sites is plotted in Figure 3, where three very different behaviors can be seen for the temperature near the ground. Nancy is characterized by strong cooling during the first half of the night (about $5 \mathrm{~K}$ ). This strong cooling is associated with a light wind at $10 \mathrm{~m}$, of less than $1 \mathrm{~ms}^{-1}$. However, cooling can be noted during the fog event at around 0000 UTC, suggesting that advection processes were present. Unfortunately, neither radiative measurements nor observations of the fog top are available at this site, and it is, therefore, very difficult to provide a detailed explanation of the physical processes leading to this behavior. Furthermore, it is out of the goal of this article. It can, however, be speculated that advections cannot be negligible during the formation of the fog layer.

Houdel is characterized by slower cooling during the first half of the night (about $2 \mathrm{~K}$ ), associated with a weak vertical gradient (less than $2 \mathrm{~K}$ in $50 \mathrm{~m}$ ). This is associated with moderate wind and strong wind shear (about $4 \mathrm{~ms}^{-1}$ at $10 \mathrm{~m}$ and $7 \mathrm{~ms}^{-1}$ at $50 \mathrm{~m}$ ). The visibility at $10 \mathrm{~m}$ is between $1000 \mathrm{~m}$ and $2000 \mathrm{~m}$ during the first half of the night. After 2230 UTC, the vertical wind shear decreases sharply, with a wind speed of about $4 \mathrm{~ms}^{-1}$ at $10 \mathrm{~m}$ and $50 \mathrm{~m}$. This is associated with a strong warming of the temperature at $50 \mathrm{~m}$. It can then be concluded that for this site, the conditions were close to fog, but turbulence and advection prevented the vertical development of the fog layer.

The OPE stations are characterized by very weak cooling and strong wind during the night while the radiative measurements show no dense fog formation despite humidity was close to $100 \%$ (not shown).

The behavior of fog was quite different at the three sites, although they are very close to each other. The variation in wind conditions are important for fog evolution; however, it is out of the goal of this paper to fully understand the detailed physical mechanisms leading to this sensitivity. Given the heterogeneities in the fog layer, it seemed very interesting to perform numerical mesoscale simulations of this case, to study the uncertainties in fog prediction and to quantify these uncertainties during the fog life cycle. 
(a) Nancy

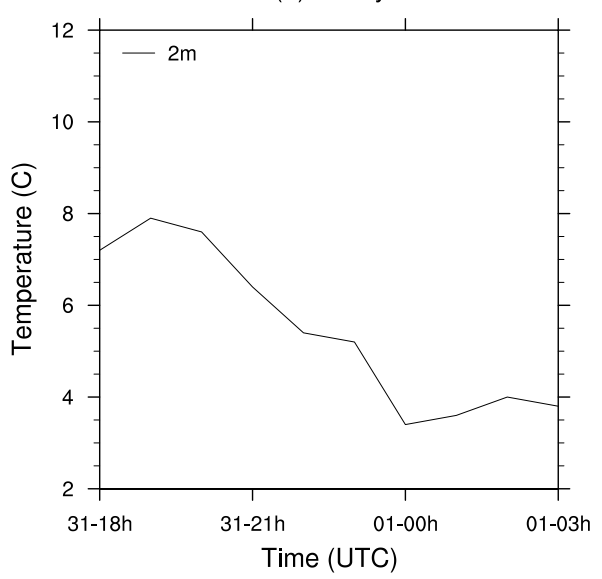

(c) Houdel

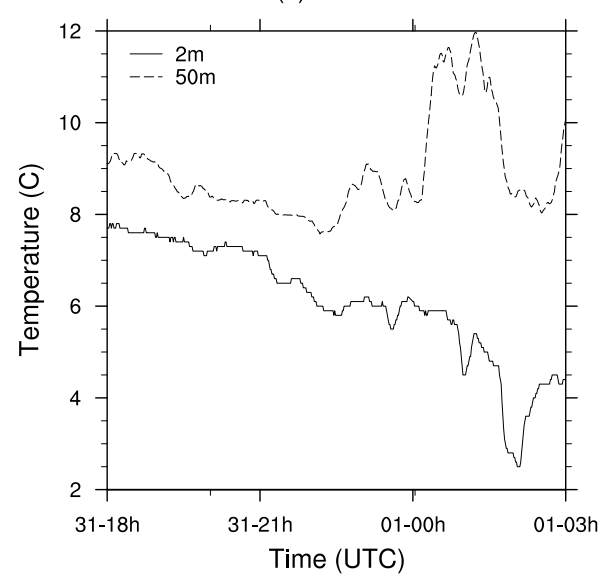

(e) OPE

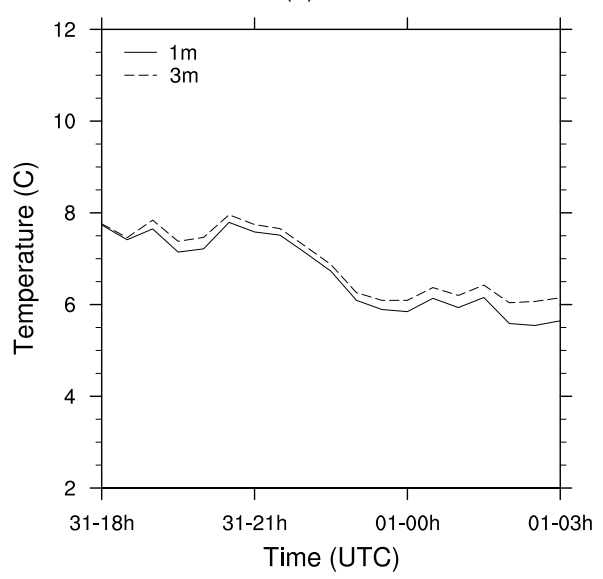

(b) Nancy

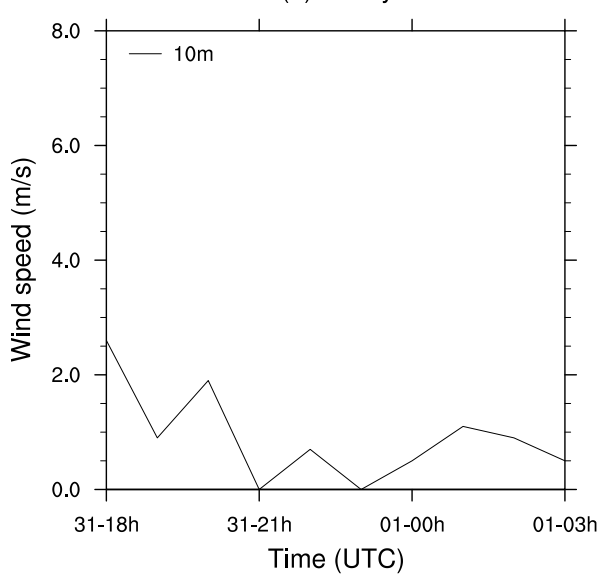

(d) Houdel

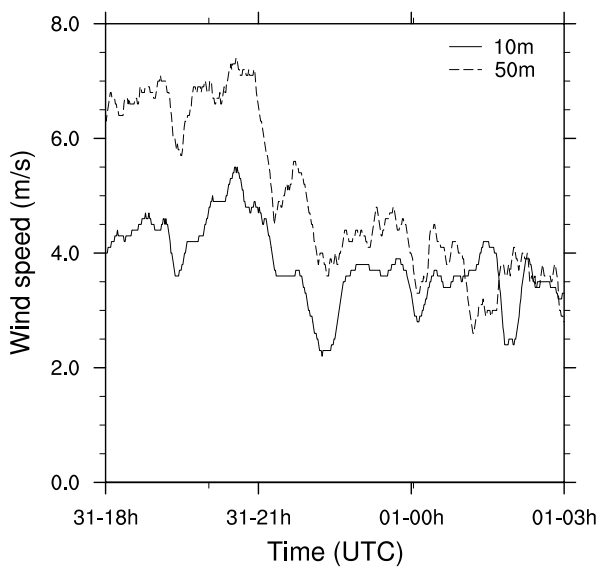

(f) OPE

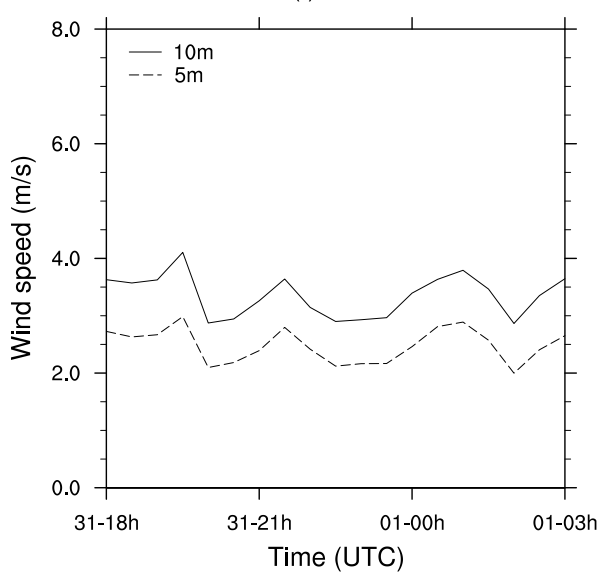

Figure 3. Temperature (left panel: a,c,e) and wind speed (right panel: $\mathbf{b}, \mathbf{d}, \mathbf{f}$ ) observed for the three observing sites.

\subsection{Model Description}

The numerical model used here is the non-hydrostatic anelastic research model Meso-NH (http:/ / mesonh.aero.obs-mip.fr). Meso-NH has been used in a large variety of configurations, from large-eddy simulations (LES) to mesoscale. It has previously been used for LES studies of neutral and stable boundary layer (e.g., Cuxart and Jimenez, 2012 [18]) and LES studies of fog over homogeneous or complex terrain (e.g., Bergot 2013 [19] and Bergot et al. 2015 [1]). Meso-NH has also been used for 
mesoscale studies and particularly for fog simulation (e.g., Bari et al., 2015 [20]) and low-level cloud studies (e.g., Sandu et al., 2008 [21]).

In the present work, the formation of fog is studied with Meso-NH in mesoscale configuration and the model setup is composed of different single models. The first model, called M500m, corresponds to a simulation at horizontal resolution of $500 \mathrm{~m}$ and includes the three observation areas (Figure 1). Three models at horizontal resolution of $50 \mathrm{~m}$ covered the three areas of observation, called M50m-OPE, M50m-Houdel and M50m-Nancy (see Figure 1) and were used to estimate the spread of the predicted parameters. The configuration of the simulations is summarized in Table 1 and they mainly correspond to the configuration used for the Météo-France operational mesoscale model. The M500m simulation was run between 1200 UTC on 31 October 2015 and 1200 UTC on 01 November 2015 and covered a region of $100 \mathrm{~km} \times 100 \mathrm{~km}$. The initial conditions and the lateral boundary conditions were taken from AROME, Météo-France's operational mesoscale model. The 50-m horizontal resolution simulations focused on the formation phase of the fog layer, which required different initialization times. M50m-OPE was run between 2000 UTC on 31 October 2015 and 0200 UTC on 01 November 2015 and covered an area of $15 \mathrm{~km} \times 10 \mathrm{~km}$ around the main site of the OPE observatory. M50m-Houdel was run between 1800 UTC on 31 October 2015 and 0300 UTC on 01 November and covered an area of $10 \mathrm{~km} \times 10 \mathrm{~km}$ around the observations made near the city of Houdelaincourt. M50m-Nancy was run between 1600 UTC on 31 October 2015 and 0200 UTC on 01 November 2015 and covered an area of 10 $\mathrm{km} \times 10 \mathrm{~km}$ around the observations made near the city of Nancy. The initial time of M50m models are chosen to explore at best the formation phase of fog. Given the fog formation time for the three area, the initial time are not the same for the three M50m models, but the simulation time cover the formation phase of the fog layer for the three studied area. The size of the M50m domains are chosen to have a best compromise between computational cost and numerical forecast accuracy. Given the mean observed wind speed, the flow in the nocturnal boundary layer entering M50m-model domain

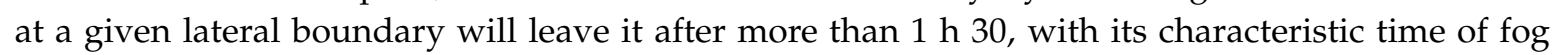
formation (e.g., Bergot et al., 2015 [1]). Both $500 \mathrm{~m}$ and $50 \mathrm{~m}$ simulations used a fine vertical resolution with 126 vertical levels. The vertical resolution was $1 \mathrm{~m}$ for the first 50 points nearest the ground and increased slightly up to $1500 \mathrm{~m}$. The time step was $6 \mathrm{~s}$ for the M500m simulation and $0.1 \mathrm{~s}$ for M50m simulations. All simulations used the same physical parameterizations, except for turbulent processes. The M500m turbulence parameterization was based on a prognostic turbulent kinetic energy equation with Bougeault and Lacarrere's (1989) [22] mixing length. The M50m used a 3D turbulent scheme based on Cuxart et al. (2000) [23] and a Deardorff mixing length (Deardorff, 1980 [24]). The turbulent scheme used in M500m and M50m are different following the previous work done with Meso-NH model (e.g., Bari et al., 2015 [20] and Bergot 2013 [19]). So, differences between M500m and M50m models are not only due to the resolution of the model but also due to difference in turbulence scheme. However, the goal of this article is to study the spread during the formation phase of fog, and not to study the effect of physical parameterization on fog forecast. The radiative transfer was computed by solving long-wave and short-wave radiative transfers separately. About microphysics, both models included the one-moment bulk microphysical scheme used in the French operational AROME mesoscale model. The liquid cloud water was calculated prognostically, but condensation and evaporation were assumed to be instantaneous. No ice was considered, given the temperature of the fog layer. The droplet sedimentation was computed by using Stokes law. The atmospheric part of the model was coupled with the Interaction between Soil, Biosphere, and Atmosphere (ISBA) model (Noilhan and Planton, 1989 [25]). Input for the geographical data was derived from the Shuttle Radar Topography Mission (https://www2.jpl.nasa.gov/srtm/france.htm) with a resolution of 1 arcsecond (about $30 \mathrm{~m}$ ). 
Table 1. Summary of model configuration.

\begin{tabular}{|c|c|c|}
\hline & M500m & M50m \\
\hline horizontal resolution & $500 \mathrm{~m}$ & $50 \mathrm{~m}$ \\
\hline horizontal domain & $200 \times 200 \mathrm{pt}$ & $\begin{array}{l}\text { M50_Nancy : } 200 \times 200 \mathrm{pt} \\
\text { M50_Houdelaincourt : } 200 \times 200 \mathrm{pt} \\
\text { M50_OPE : } 300 \times 200 \mathrm{pt}\end{array}$ \\
\hline vertical resolution & $\begin{array}{c}126 \text { levels } \\
\text { first level } 0.5 \mathrm{~m} \\
50 \text { levels in the lowest } 50 \mathrm{~m} \\
\text { top at } 1500 \mathrm{~m}\end{array}$ & $\begin{array}{c}126 \text { levels } \\
\text { first level } 0.5 \mathrm{~m} \\
50 \text { levels in the lowest } 50 \mathrm{~m} \\
\text { top at } 1500 \mathrm{~m}\end{array}$ \\
\hline time step & $6 \mathrm{~s}$ & $0.1 \mathrm{~s}$ \\
\hline initial conditions & $\begin{array}{l}\text { operational AROME model }(1.3 \mathrm{~km}) \\
31 / 10 / 2015 \text { at } 1200 \mathrm{UTC}\end{array}$ & $\begin{array}{l}\text { M500m } \\
\text { M50m_Nancy : } 31 / 10 / 2015 \text { at } 1600 \text { UTC } \\
\text { M50m_Houde : } 31 / 10 / 2015 \text { at } 1800 \text { UTC } \\
\text { M50m_OPE : } 31 / 10 / 2015 \text { at } 2000 \text { UTC }\end{array}$ \\
\hline lateral boundary conditions & operational AROME model $(1.3 \mathrm{~km})$ every $3 \mathrm{~h}$ & M500m every $15 \mathrm{~min}$ \\
\hline orography & $\operatorname{srtm} 1(30 \mathrm{~m})$ & $\operatorname{srtm} 1(30 \mathrm{~m})$ \\
\hline land cover & ecoclimap $(1 \mathrm{~km})$ & ecoclimap $(1 \mathrm{~km})$ \\
\hline turbulence scheme & $\begin{array}{l}\text { 1D (Cuxart et al., } 2000 \text { [23]) } \\
\text { mixing length : Bougeault and Lacarrere (1989) [22] }\end{array}$ & $\begin{array}{l}\text { 3D (Cuxart et al., } 2000 \text { [23]) } \\
\text { mixing length : Deardorff (1980) [24] }\end{array}$ \\
\hline microphysical scheme & ICE3 (Pinty and Jabouille, 1998 [26]) & ICE3 (Pinty and Jabouille, 1998 [26]) \\
\hline surface scheme & ISBA (Noilhan and Planton, 1989 [25]) & ISBA (Noilhan and Planton, 1989 [25]) \\
\hline radiation scheme & $\begin{array}{l}\text { long-wave : RRTM (Mlawer et al., } 1997 \text { [27]) } \\
\text { short-wave : Morcrette (1991) [28] }\end{array}$ & $\begin{array}{c}\text { long-wave : RRTM (Mlawer et al., } 1997 \text { [27]) } \\
\text { short-wave : Morcrette (1991) [28] }\end{array}$ \\
\hline
\end{tabular}

\section{Results of Numerical Simulations}

In this Section, the main characteristics of the simulated fog layer are studied. We focus on the fog onset and the initial development of the fog layer. The behavior of the simulations is first studied at mesoscale for the three areas. The main goal is to verify that the model can simulate the main behavior of the fog onset at mesoscale, namely the formation of a dense fog layer at Nancy, formation of patchy fog at Houdel and no fog at OPE. Afterwards, the spread of the predicted parameters is studied by exploring the fine resolution simulation (M50m).

\subsection{Formation of Fog at Mesoscale}

The fog onset time for the M500m simulation is plotted in Figure 4. The fog is formed in the beginning of the night in the south-east of the domain. The fog layer very quickly becomes deep and then dense. Then, it spreads northward, following the valleys. In the Nancy area, the fog is formed near 2100 UTC, and becomes mature around 0000 UTC. This timing agrees with the observations. The Houdel region is in a transient area between fog and no-fog. Near Houdel, the fog is formed at ground level around 2230 UTC but does not develop vertically and remains confined to the valley around the site. The modelled fog can be seen to propagate along a wide valley between Nancy and Houdel, reaching the north-west of the region easily. However, the narrow valleys located to the west of the Houdel and OPE regions lead to very localized fog channeled through the valleys. The OPE site remains free of fog, even though it is surrounded by fog in the middle of the night. Finally, the fog is not formed in the western part of the domain even though the area is relatively flat.

The modelled liquid water path (LWP) and the wind at $10 \mathrm{~m}$ are plotted in Figure 5. It confirms that the wind is weaker in the wide valley in the east of the domain. At first, a dense fog layer appears in the south-east of the domain and propagates rapidly along the valley. The fog at Nancy could be considered as a mature adiabatic fog from the middle of the night (LWP $>25 \mathrm{gm}^{-2}$ ). The wind is stronger in the western part of the domain, about $4 \mathrm{~ms}^{-1}$ at $10 \mathrm{~m}$ with maximum values of the order of $5 \mathrm{~ms}^{-1}$. A very complex circulation can be noted, which seems to be mainly driven by the hills and 
valleys. The hills oriented north-south in the middle of the domain are associated with an acceleration of the wind. Figure 5 also confirms that only patchy fog appears at Houdel, with a low value of LWP. This site is located at the border of the foggy area during the night. The OPE site, located in the western part of the hills, is exposed to a sustained wind, without fog.

To conclude, this event is a quite complex case with numerous interactions and complex circulations. It is interesting to explore the consequences of these circulations to forecast uncertainties.

(a) $\mathrm{M} 500 \mathrm{~m}$

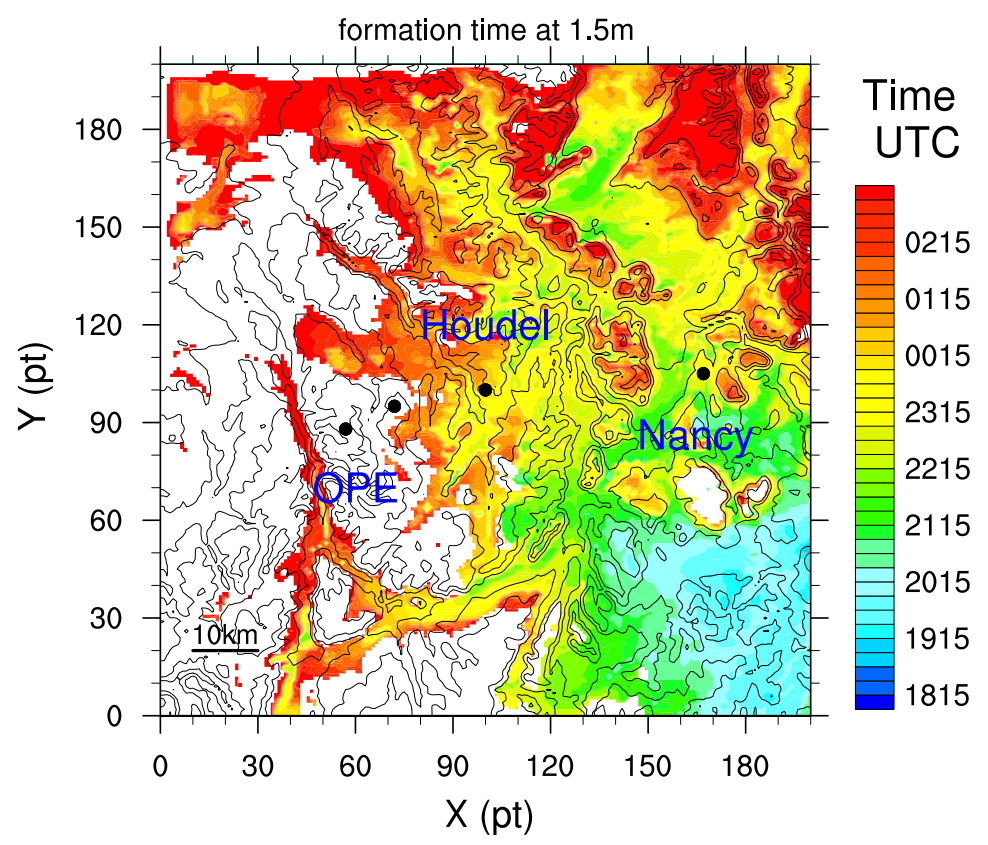

(b) $\mathrm{M} 500 \mathrm{~m}$



Figure 4. Fog onset time (UTC) at ground level (a) and at $50 \mathrm{~m} \mathrm{(b)}$ for the M500m model superimposed with the topographical features (contours every $50 \mathrm{~m}$ ). The black dots indicate the locations of the observation sites. 
(a) M500m - 1800UTC

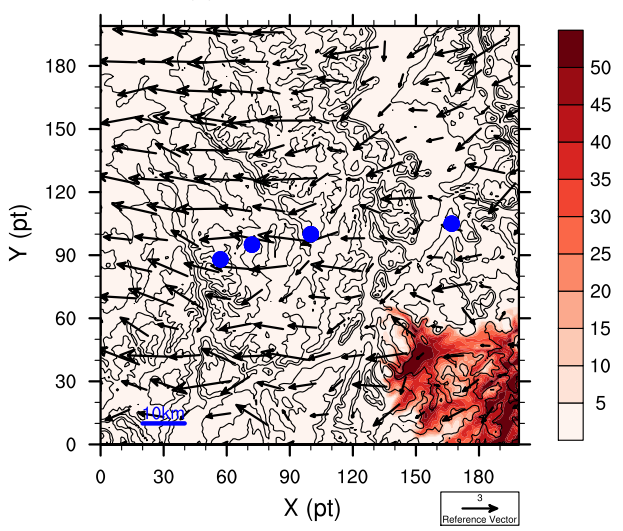

(c) M500m - 0000UTC

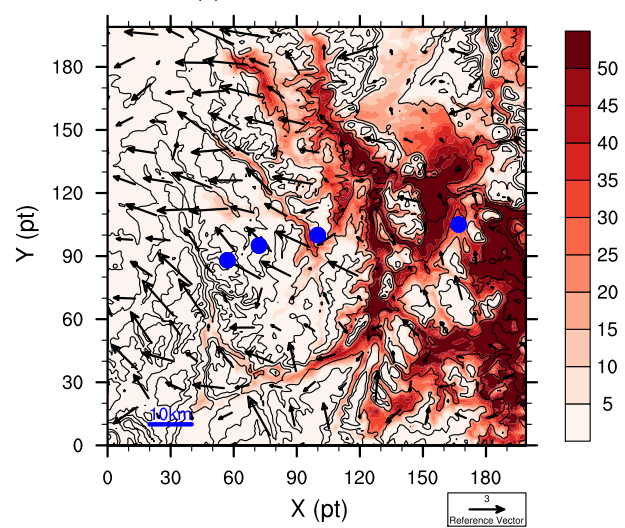

(b) M500m - 2100UTC

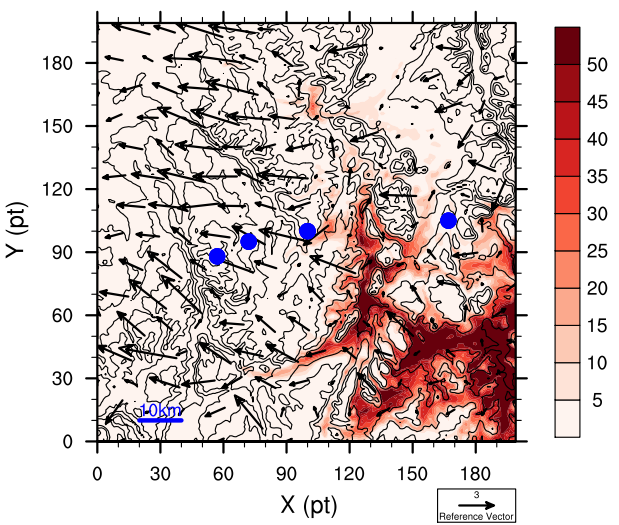

(d) M500m - 0300UTC

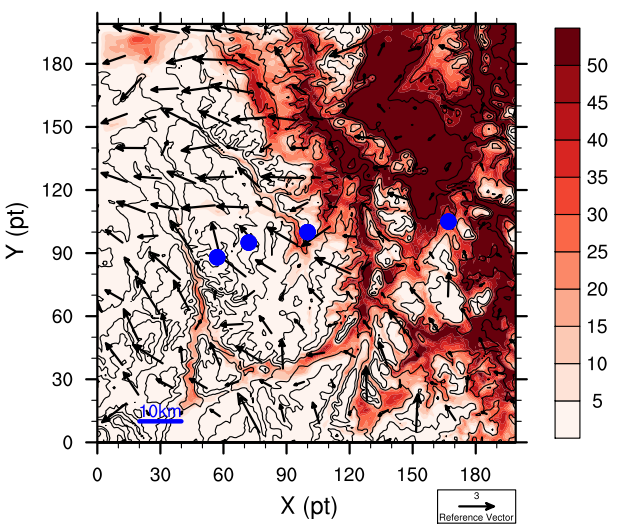

Figure 5. Liquid water path (LWP, gm ${ }^{-2}$ ) at 1800 UTC (a), 2100 UTC (b), 0000 UTC (c) and 0300 UTC (d) for the M500m model superimposed with orography (thin black lines, contours every $50 \mathrm{~m}$ ) and wind speed at $10 \mathrm{~m}\left(\mathrm{~ms}^{-1}\right)$. The blue dots indicate the locations of the observation sites.

\subsection{Study of the Spread}

Figure 6 shows that M500m and M50m simulations are close regarding the fog onset whatever the region is. However, thermodynamic parameters, such as wind and temperature, were also studied to illustrate the spread of the predicted parameters and to discuss the predictability of fog.

\subsubsection{Nancy}

At Nancy, the fog is formed at ground at 2030 UTC for both simulations, which is close to observation (fog first observed at 2100 UTC, with observations every hour). However, spread in predicted liquid water content (LWC) can be found during the development of the fog layer (Figure 6). Until 2230 UTC, the LWC at $2 \mathrm{~m}$ of the M500m simulation is about half that of M50m. It can also be noted that this difference is beyond the spread of M50m at 500-m resolution. The increase in LWC at about 2230 UTC for both simulations is linked with the variation of the wind intensity (Figure 7). At this time, the wind at $50 \mathrm{~m}$ strongly weakens. Both simulations reproduce this behavior in the same way and the spread is very small for the wind. Unfortunately, observations of wind at 50-m height are not available for Nancy but observations of the wind at 10-m height confirm its weakening until 0000 UTC, followed by a small increase when the fog becomes mature. The uncertainties of the wind intensity prediction were, therefore, weak. The cooling is well reproduced whatever the simulation (Figure 8) and there is little spread in temperature or wind. It can be concluded that during the fog formation at Nancy meteorological parameters showed weak spread and this fog event is highly predictable except relatively small spatial variability of fog around the fog onset time. 
(a) Nancy

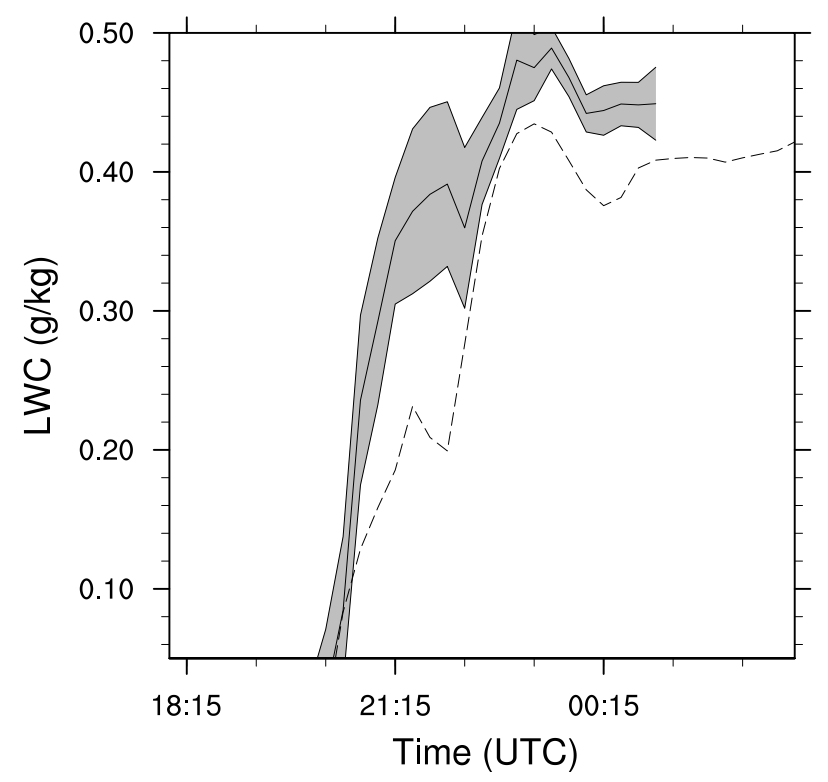

(b) Houdel

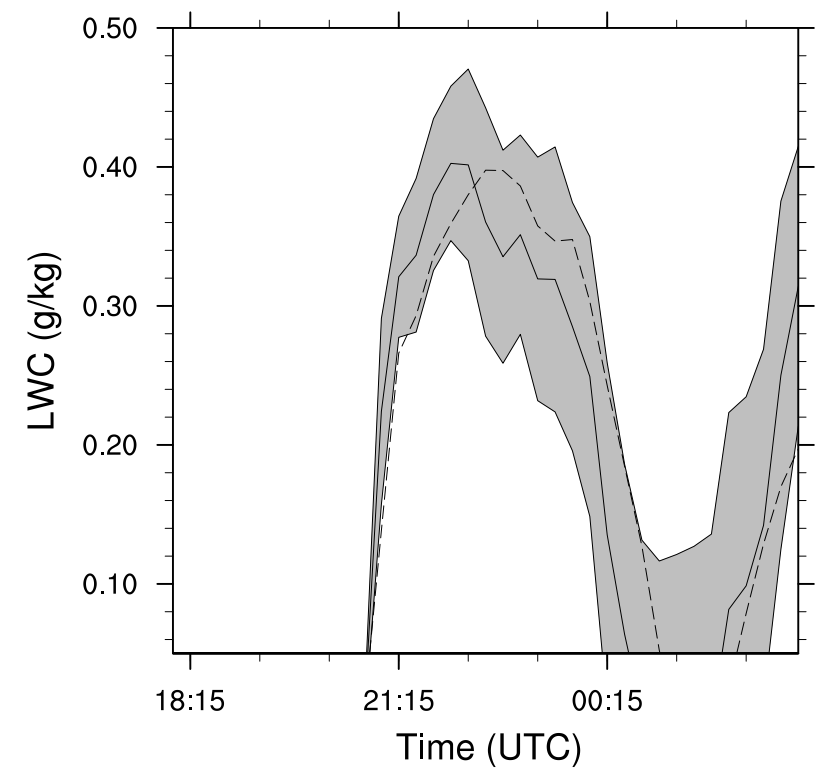

Figure 6. Time series of liquid water content (LWC) at $2 \mathrm{~m}$ for Nancy (a) and Houdel (b). M500m is represented by a dashed line and M50m by a solid line. The standard deviations of M50m at $500 \mathrm{~m}$ horizontal scale are indicated by the grey areas.

\subsubsection{Houdel}

At Houdel, a patchy fog is simulated whatever the horizontal resolution used. The life cycle of fog simulated by M500m and M50m is similar (Figure 6). Two short foggy events were observed, one at about 2330 UTC and the other at about 0200 UTC (Figure 2). Two patchy fog events are also simulated, but one begins too early—about 2100 UTC — and the other at about 0200 UTC, in agreement with observations. Significant spread of the simulated LWC at $2 \mathrm{~m}$ is noteworthy.

The simulated cooling at $2 \mathrm{~m}$ is identical for both models until $0000 \mathrm{UTC}$; the spread is small (Figure 8). The simulation confirms a significant rise in temperature at 50-m height. The amplitude of this warming (about $3 \mathrm{~K}$ ) agrees with observations. However, the spread of the simulated temperature at 50-m height is large during the night. This illustrates that advection processes, particularly near 
50-m height, showed a strong spatial variability. These advection processes are highly unpredictable at mesoscale.

The wind speed at Houdel is significantly higher than at Nancy during the night (Figure 7). The spread is relatively large, at the order of $2 \mathrm{~ms}^{-1}$ at $10 \mathrm{~m}$ and $50 \mathrm{~m}$. However, the tendency of the wind speed is quite well simulated. The wind at $50 \mathrm{~m}$ height decreases during the night, from about $7 \mathrm{~ms}^{-1}$ in the beginning of the night to about $4 \mathrm{~ms}^{-1}$ in the middle of the night. It can be concluded that the nocturnal thermal inversion is highly unpredictable mainly due to moderate wind and local advections. This leads to significant spread in LWC near the ground, and consequently uncertainties in the forecasted time in which fog became mature.

(a) Nancy

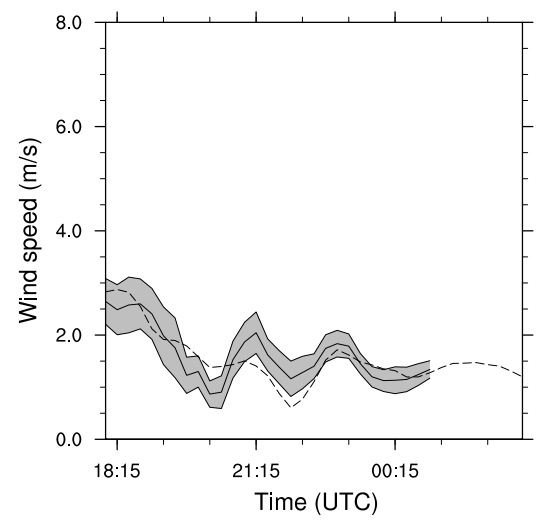

(c) Houdel

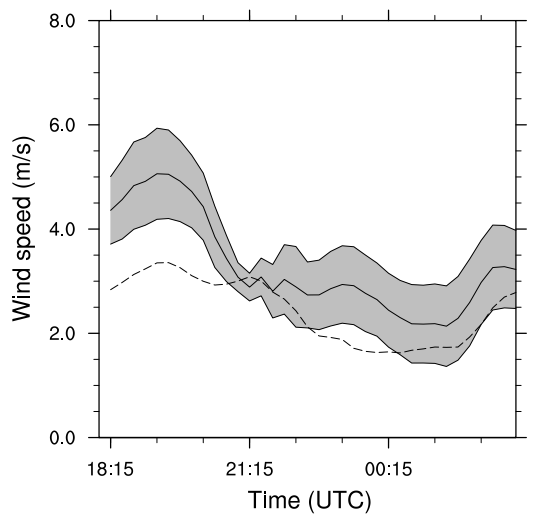

(e) OPE

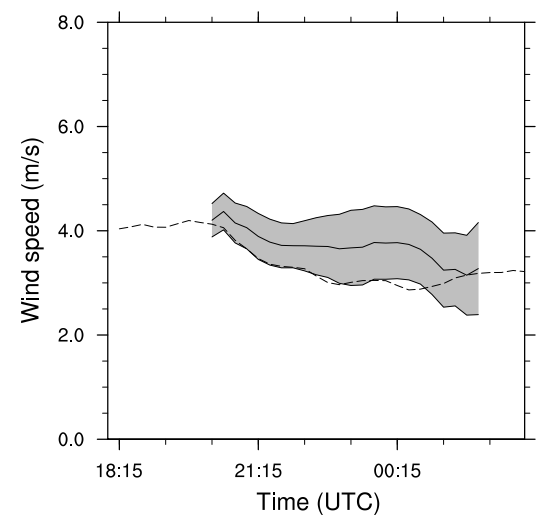

(b) Nancy

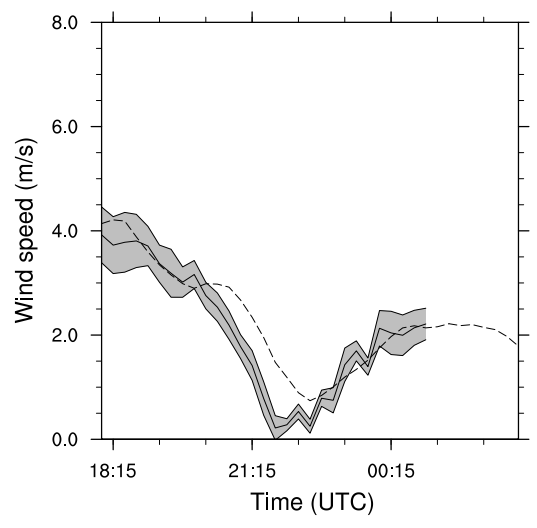

(d) Houdel

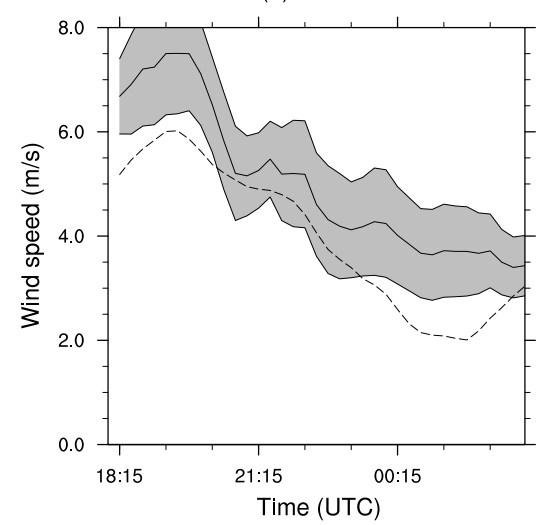

(f) OPE

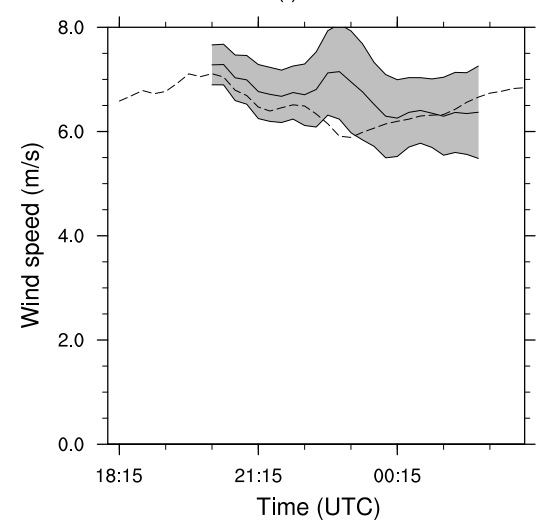

Figure 7. Time series of modelled wind speed at $10 \mathrm{~m} \mathrm{~m}$ (left panel: a,c,e) and at $50 \mathrm{~m}$ (right panel: $\mathbf{b}, \mathbf{d}, \mathbf{f})$ for Nancy, Houdel, and OPE. The grid point value for the observed sites is represented by the dashed line for M500m and by solid line for M50m. The standard deviations at $500 \mathrm{~m}$ horizontal scale are indicated by the grey areas. 
(a) Nancy

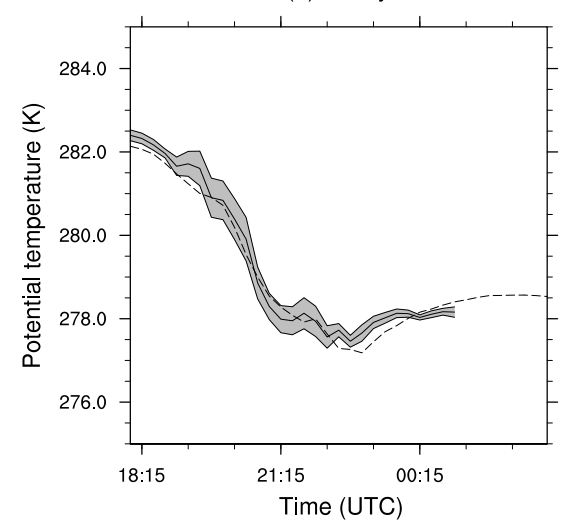

(c) Houdel

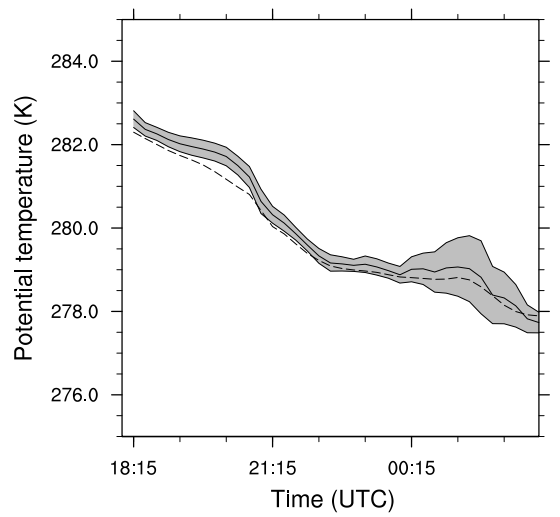

(e) OPE

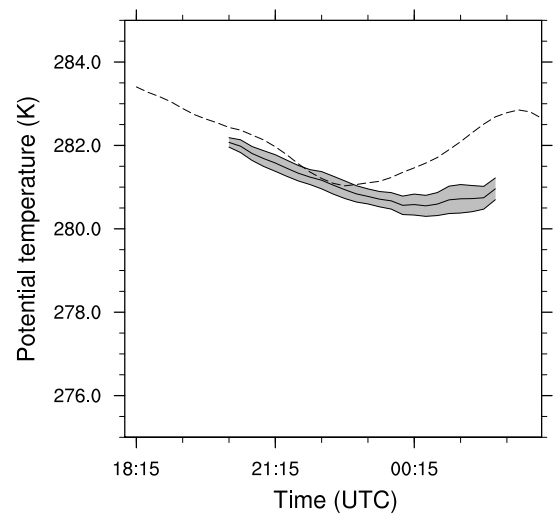

(b) Nancy

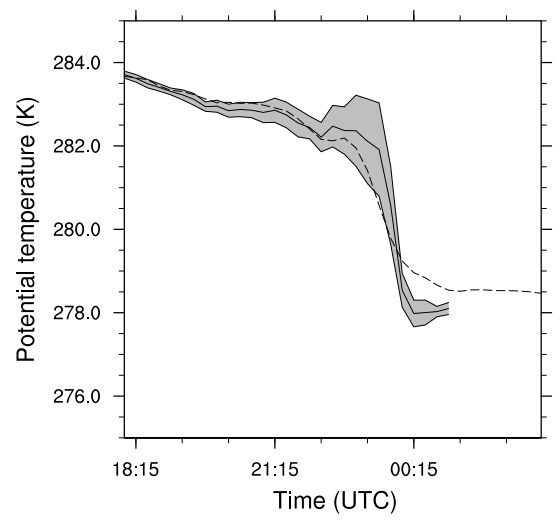

(d) Houdel

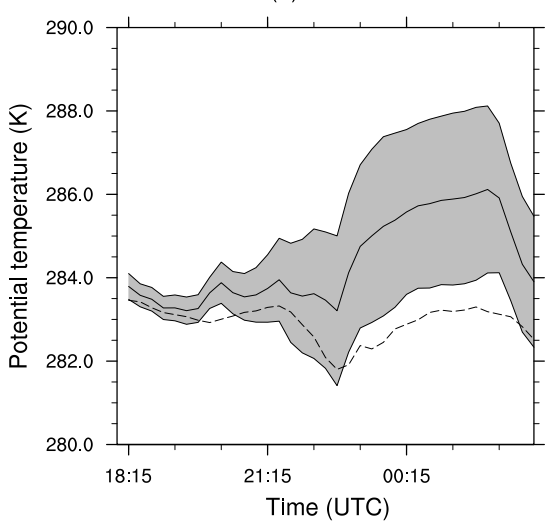

(f) OPE

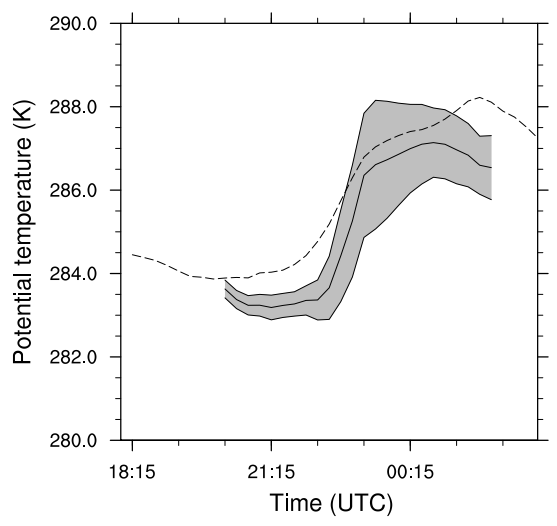

Figure 8. Time series of modelled potential temperature at $2 \mathrm{~m}$ (left panel: a,c,e) and at $50 \mathrm{~m}$ (right panel: b,d,f) for Nancy, Houdel, and OPE. The grid point value for the observed sites is represented by the dashed line for $\mathrm{M} 500 \mathrm{~m}$ and by solid line for $\mathrm{M} 50 \mathrm{~m}$. The standard deviations at $500 \mathrm{~m}$ horizontal scale are indicated by the grey areas. 


\subsubsection{OPE}

At OPE, about $15 \mathrm{~km}$ to the west of Houdel, fog is neither observed nor simulated.

The cooling at $2 \mathrm{~m}$ is weak, less than $2 \mathrm{~K}$, for both simulations (Figure 8); the spread is less than $0.2 \mathrm{~K}$. The modelled mean cooling agrees with the observations, though differences can be noticed in the middle of the night. The temperature at 50-m height shows strong warming (about $4 \mathrm{~K}$ ) in the middle of the night but the spread is smaller than that modelled at Houdel.

The wind speed at $10 \mathrm{~m}$ (Figure 7) is correctly simulated in both simulations, and is similar to the observed wind. The major difference with the two previous sites is that the wind at $50 \mathrm{~m}$ remains strong, with a speed of about $7 \mathrm{~ms}^{-1}$, during the night. It is also interesting to note that even if the spread of the simulated wind is similar to that at Houdel, no clear tendency could be observed. It can be concluded that despite predicted parameters showed significant spread, these uncertainties have no impact on fog forecasting.

\section{Predictability of the Fog Evolution}

This Section discusses the predictability of the case studied. Specifically, we study the predictability of fog during the formation phase at the three locations, Nancy, Houdel, and OPE, using the M50m simulation.

\subsection{Spatial Heterogeneity of Fog}

First, we focus on the spatial heterogeneity of the fog at ground level for different horizontal scales. To do this, the spatial coverage of fog is computed in three squares with sides $1 \mathrm{~km}, 5 \mathrm{~km}$ and $10 \mathrm{~km}$ centered at the observation sites. The first noteworthy feature is that the occurrence of fog at a horizontal scale of $1 \mathrm{~km}$ is very close to the occurrence of fog at the grid point (Figure 9). At grid point or at $1 \mathrm{~km}$-scale, the duration of the formation phase is very short, less than $30 \mathrm{~min}$. This is not in agreement with recent LES results (e.g., Bergot et al. 2015 [1]) or observations (e.g., Price et al. 2018 LANFEX IOP12 [2]). The occurrence of fog at 5km-scale and 10km-scale are similar; however, at these scales, the duration of the formation phase is longer and more in agreement with LES results or observations.

The formation phase of fog can be defined by the time for which the fog coverage is between $5 \%$ and $95 \%$. Regarding Nancy, the duration of the formation phase is about $30 \mathrm{~min}$ at $1 \mathrm{~km}$-scale, about $3 \mathrm{~h}$ at $5 \mathrm{~km}$-scale and about $4 \mathrm{~h}$ at $10 \mathrm{~km}$-scale. For Houdel, the formation of the first fog episode is quite similar at $1 \mathrm{~km}$-scale but lasts longer at $5 \mathrm{~km}$-scale (about $2 \mathrm{~h}$ ) and $10 \mathrm{~km}$-scale (about $3 \mathrm{~h}$ ). However, two short foggy events were simulated and observed. If the end of the formation phase (i.e., the beginning of the mature phase) is defined as the time when the second fog event covers more than $95 \%$ of the studied area, the formation phase is considerably longer at Houdel (about $7 \mathrm{~h}$ ), whatever the horizontal scale considered.

Now, we are focusing on the fog coverage at the local fog onset time for the three studied areas. At Nancy, the fog coverage is about $85 \%$ at this time. It can be concluded that the fog onset time at Nancy corresponds to a fairly homogeneous fog layer, whatever the spatial scale studied. The situation is rather different at Houdel. The spatial coverage at local onset time is of the order of $50 \%$. The fog layer is considerably patchier at Houdel during the formation phase. At OPE, fog does not form around the observation site. However, the maximum fog coverage is about $30 \%$ at $10 \mathrm{~km}$-scale, illustrating that the situation is favorable to fog formation. 
(a) Nancy M50m

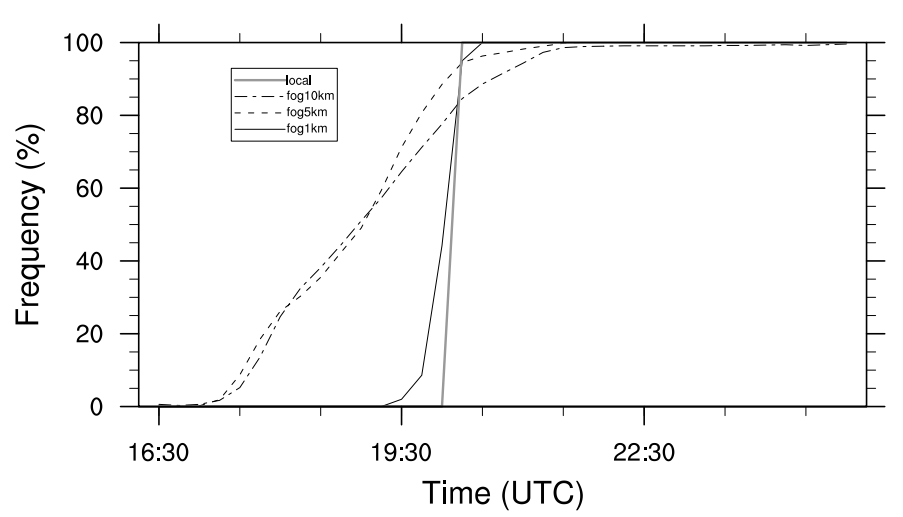

(b) Houdel M50m

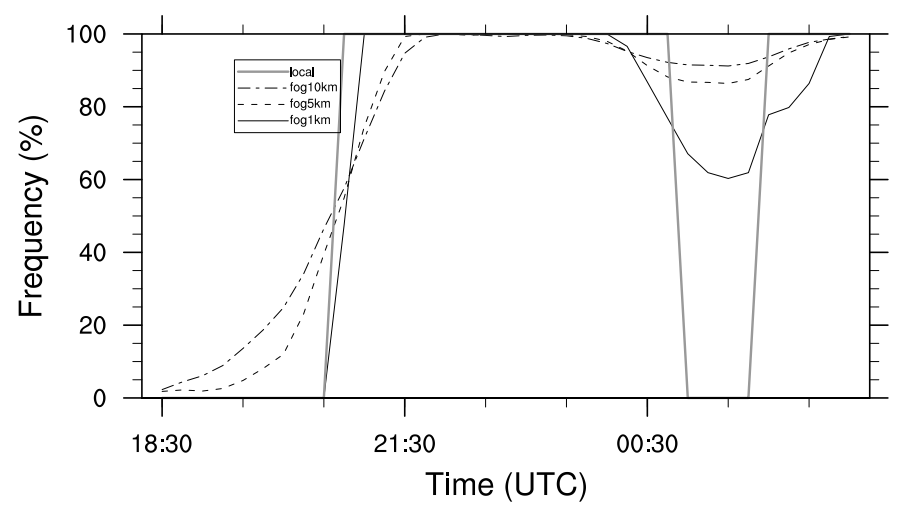

(c) OPE M50m

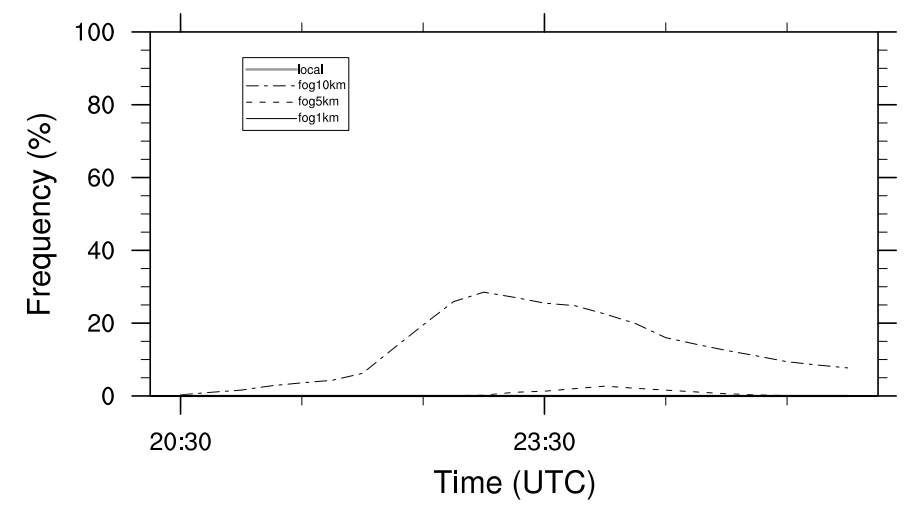

Figure 9. Evolution of the fog coverage at the three observation sites: Nancy (a), Houdel (b) and OPE (c). Coverage is computed at the site points—see Figure 1 (solid grey line), over $1 \mathrm{~km} \times 1 \mathrm{~km}$ (solid black line), over $5 \mathrm{~km} \times 5 \mathrm{~km}$ (dashed line) and over $10 \mathrm{~km} \times 10 \mathrm{~km}$ (dot-dashed line).

\subsection{Pseudo-Process Diagram}

In this study, we have used the process diagram paradigm proposed by Steeneveld and De Bode (2018) [14] to explore the uncertainties in the model simulations. The process diagram is a relatively new concept to explore model uncertainties. The main goal is to highlight the dominant processes generating forecast spread by plotting the model prediction in model parameter space. The focus, here, is on the $\mathrm{M} 50 \mathrm{~m}$ results at $1 \mathrm{~km}$-scale and $5 \mathrm{~km}$-scale, to illustrate the spread of the results during the formation phase. This could be seen as an estimation of an ensemble spread. However, it is not currently possible to have at 50-m resolution ensemble forecast. To overcome this problem, 
the members are here defined as the forecast at different grid points. These ensemble forecast members could be seen as forecast members with different surface and atmosphere conditions but with the same physical processes given by the model, which is considered to be perfect. Price (2011) [29] identified that only $50 \%$ of fog cases evolved into deep and optically thick fog, associated with saturated adiabatic temperature profiles. The other $50 \%$ remained shallow and optically thin, associated with thermally stable layer near the ground. Shallow and deep fogs and thus quite different and identifying if fog becomes deep is clearly an important forecast goal. To explore this, the surface net radiation flux (Rnet) and the mean vertical temperature gradient $(\mathrm{dT} / \mathrm{dz})$ are plotted in the proposed pseudo-process diagram. In this pseudo-process diagram, each point corresponds to the coupling between Rnet and $\mathrm{dT} / \mathrm{dz}$ for the studied area and the time interval studied. The main goal is to differentiate shallow fog, associated with strongly negative Rn and thermal inversion, from deep fog, associated with weak Rn and thermal gradient. Figure 10 correlates the surface net radiation flux (Rnet) and the mean vertical gradient of temperature in the first $50 \mathrm{~m}(\mathrm{dT} / \mathrm{dz})$. This pseudo-process diagram allows us to investigate the spread during formation phase of the fog layer. Rnet is characteristic of fog depth because no clouds (except fog) are simulated. Three different patterns are found for the three observation sites.

\subsubsection{Nancy}

The pseudo-process diagram for Nancy plotted in Figure 10 is typical of radiation fog formation. In a first phase, Rnet is strongly negative and associated with a thermal inversion. The small increase in Rnet and an increase in stability are linearly correlated. This phase is characterized by a relatively small spread and the trajectories in phase space are in a fairly narrow area, even at $5 \mathrm{~km}$-scale.

In a second phase, the stability is nearly constant but a chaotic variation of Rnet is observed. During this transition phase, saturation is reached, and numerous patches of shallow fog appear. Furthermore, the mixing inside the nocturnal boundary layer is small due to strong thermal stratification and sporadic randomness appearing inside the patchy fog layer. This phase is highly sensitive to small perturbations in dynamical, microphysical, turbulence, land-surface exchanges or advections, which could have a strong impact on the fog life cycle. This can be seen in the spread of the pseudo-process diagram during this phase. Here, the variability is only due to surface heterogeneities. The pseudo-process diagram demonstrated a sensitivity of fog forecasting during this phase. However, the spread illustrated by the pseudo-process diagram might still be smaller than variability induced to variations in physical parameterizations. An ensemble prediction system seems to be necessary to improve the fog prediction, and particularly during the formation phase.

A final phase corresponds to a deep adiabatic fog layer, where Rnet and vertical gradient are close to zero. The thermal inversion is broken very quickly, and this phase is linked with weak spread.

To sum up, two attractors are exhibited that describe two stable states of the atmosphere corresponding to no-fog and deep fog. A regime transition between these two states corresponds to shallow patchy fog and is chaotic by nature.

\subsubsection{Houdel}

The pseudo-process diagram for Houdel (Figure 10) shows a different behavior. Rnet is seen to increase quickly under weak vertical stratification. This is characteristic of an advection of a fog layer, associated with a moderate wind (Figure 7). Moderate wind implies also weak thermal stratification, which is associated with upward mixing of foggy air. The turbulent mixing allows evaporation of the advected fog layer, and consequently a decrease in Rnet. The decrease in the wind speed during the night and thus warm air advection leads to an increase in the thermal stratification. The spread is huge during the night, and there is an increase in the spread at $5 \mathrm{~km}$-scale. In this case, the fog formation evolution is less predictable than for Nancy. However, the two attractors are again observed, defined by no-fog and deep fog conditions. The trajectories in phase space are complex and no preferred trajectories could be found between these two states. However, this case study demonstrates that a pseudo-process diagram might enable to distinguish directly between advection and radiation fog. 
(a) Nancy $-1 \mathrm{~km}$

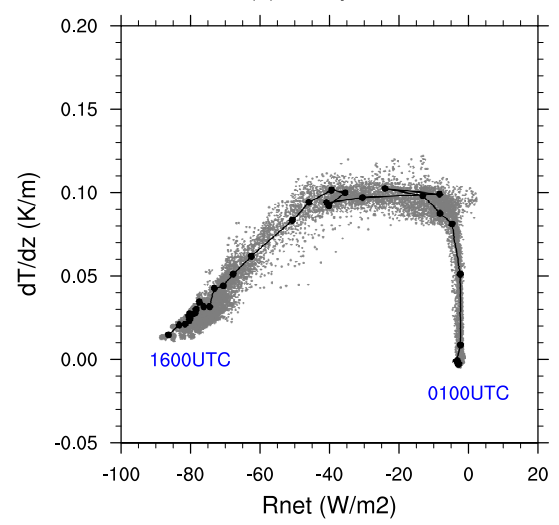

(c) Houdel $-1 \mathrm{~km}$

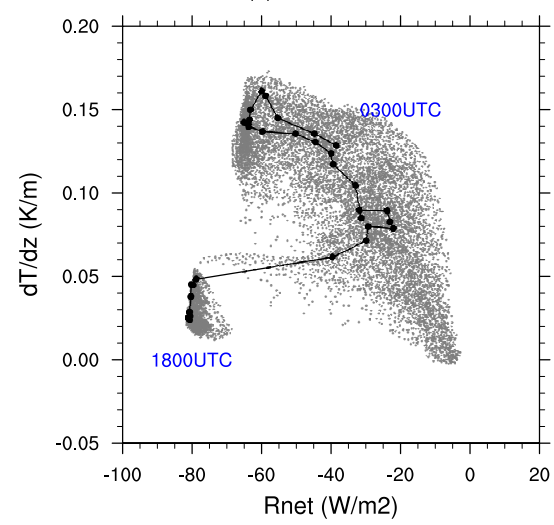

(e) OPE - $1 \mathrm{~km}$

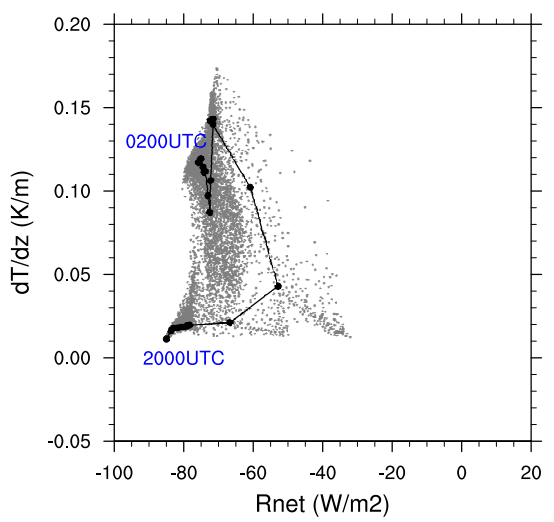

(b) Nancy -5km

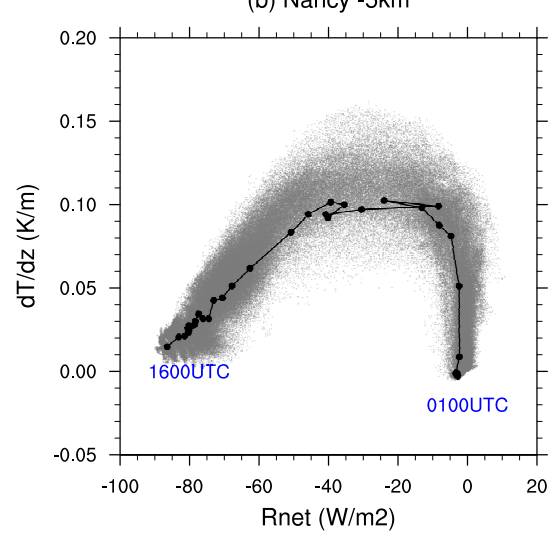

(d) Houdel $-5 \mathrm{~km}$

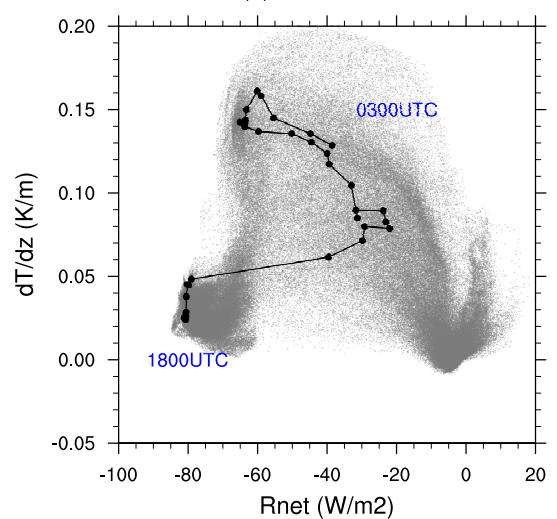

(f) OPE -5km

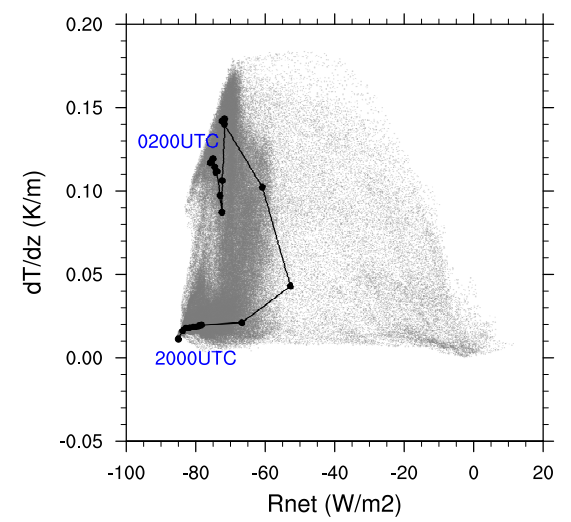

Figure 10. Pseudo-process diagrams between the modelled net radiation fluxes at the surface (Rnet) and modelled surface layer stability (dT/dZ) for the three observation sites : Nancy (a,b), Houdel (c,d) and OPE (e,f). Diagrams are plotted over an area of $1 \mathrm{~km} \times 1 \mathrm{~km}$ (left panel: a,c,e) and over an area of $5 \mathrm{~km} \times 5 \mathrm{~km}$ (right panel: $\mathbf{b}, \mathbf{d}, \mathbf{f}$ ). The trajectory for the observed site is plotted by solid line.

\subsubsection{OPE}

The pseudo-process diagram for OPE (Figure 10) is typical of no-fog conditions. The Rnet stays strongly negative, but a strong spread of the thermal stratification can be noted. No correlation could be found between the two parameters. Although the forecast depends strongly on the turbulent processes (i.e., thermal stratification), the predictability for OPE seems large and points to a no-fog situation. The spread in Rnet is stronger at $5 \mathrm{~km}$-scale than at $1 \mathrm{~km}$-scale, showing that some grid points reach the foggy condition for scales greater than $5 \mathrm{~km}$ (Figure 9). 
These numerical simulations demonstrate that occurrences and types of fog could be very different over a small but heterogeneous area, which corroborates the findings of Bari et al. (2015) [20]. The variability is mainly concentrated during the regime transition between shallow stable fog and deep adiabatic fog and is the result of the complex interplay of local and non-local influences at a large range of scales. The surface heterogeneities strongly affect the bifurcation between shallow and deep fog in a complex way. However, a pseudo-process diagram could be helpful to quantify the spread during the fog life cycle and consequently to quantify the predictability of fog.

\section{Conclusions and Perspectives}

Fog is a high-impact weather phenomenon and the evolution of a shallow fog to a deep adiabatic one is still not well-understood. However, knowledge of the evolution of fog between its formation phase and its mature phase is essential to improve the prediction of fog and to better reduce its societal impact. The duration of a fog event depends strongly on this transition phase. While a mature fog can last several hours after sunrise, shallow fogs dissipate very quickly. The consequences for airport traffic can be totally different and it seems crucial to precisely forecast the evolution of a fog during the formation phase.

In this study, the formation phase of an advection-radiation fog observed in the north-east of France has been studied with the Meso-NH numerical mesoscale model. The evolution of fog during its formation phase is very complex and the behavior of the fog layer can differ greatly over an area of a few kilometers. Occurrences and types of fog can vary within heterogeneous areas. This variability is concentrated during the formation phase and is the result of complex interactions between physical processes at numerous scales. The spread of mean parameters appears mainly during the evolution between shallow fog and deep adiabatic fog, showing that there is loss of predictability during this period. Also, wind at the top of the nocturnal boundary layer plays a significant role during the bifurcation from formation to mature phases. By modifying the mixing between the nocturnal boundary layer and the residual layer, modestly stronger wind can alter the development of the fog layer and keep fog in a shallow patchy state.

To explore the regime transition between shallow and deep fog, a new paradigm called pseudo-process diagram has been proposed. This diagram correlates the net surface radiative flux with the thermal stratification. Pseudo-process diagrams have proved to be a very efficient tool for exploring the spread and type of fog. The evolution of a fog layer can be summarized by two attractors, defined by no fog and deep fog states. The trajectories in the phase space between these attractors correspond to a bifurcation during the fog life cycle. The most attractive feature of the pseudo-process diagram paradigm is that complex systems such as fog may exhibit similar behavior, whatever the physical processes involved in the transition phase (e.g., microphysics, turbulence, surface-atmosphere interactions). This regime transition between shallow and deep fog is chaotic by nature. However, pseudo-process diagrams can provide a good illustration of the fog spread between the two attractors. Moreover, a pseudo-process diagram might enable to distinguish between radiation and advection fog, and could be, therefore, very fruitful while exploring data from field experiments.

It seems necessary to precisely quantify the uncertainties in a fog forecast, and ensemble forecasts seem to be a useful tool. Preliminary work has been done by Roquelaure and Bergot (2009) [30] with the 1D Cobel-ISBA fog prediction system. By better understanding the spread of fog, one can hope to better understand the physical processes driving the fog life cycle. Pseudo-process diagrams have demonstrated to be a fruitful tool to explore the fog forecast. Ensemble forecasts using suitable perturbations representative of the sensitivities of fog forecasting appear to be essential if progress is to be made in the domain of fog prediction. This study has demonstrated that the wind at the top of the nocturnal boundary layer has a significant impact during the transition between shallow and deep fog, and it will be necessary that fog ensemble forecast system represents at best the wind spread inside the boundary layer. 
Author Contributions: T.B. conceived the experimental framework; R.L. performed the numerical computation; R.L. and T.B. contributed to the interpretations of the results; T.B. wrote the manuscript with inputs from R.L.

Funding: This research received no external funding.

Acknowledgments: We gratefully thank the Observatoire Pérenne de l'Environnement (OPE) for providing us with the observations that allowed us to perform this study, and particularly Sebastien Conil (ANDRA) and Marie-Pierre Turpault (INRA). We thank Driss Bari (Maroc Meteo) for fruitful discussions and his valuable comments on an earlier draft of this paper. The support team of Meso-NH is acknowledged for their help during this study.

Conflicts of Interest: The authors declare no conflict of interest.

\section{References}

1. Bergot, T.; Escobar, J.; Masson, V. Effect of small-scale surface heterogeneities and buidings on radiation fog: Large-eddy simulation study at Paris-Charles de Gaulle airport. Q. J. R. Meteorol. Soc. 2015, 141, 285-298. [CrossRef]

2. Price, J.D.; Lane, S.; Boutle, I.A.; Smith, K.D.E.; Bergot, T.; Lac, C.; Duconge, L.; McGregor, J.; Kerr-Munslow, A.; Pickering, M.; et al. LANFEX: A field and modelling study to improve our understanding and forecasting of radiation fog. Bull. Am. Meteorol. Soc. 2018, 99, 2061-2077. [CrossRef]

3. Boutle, I.; Price, J.; Kudzotsa, I.; Kokkola, H.; Romakkaniemi, S. Aerosol-fog interaction and the transition to well-mixed radiation fog. Atmos. Chem. Phys. 2018, 18, 7827-7840. [CrossRef]

4. $\quad$ Roach, W.T.; Brown, R.; Caughey, R.; Garland, S.J.; Readings, C.J. The physics of radiation fog: I - A field study Quart. J. R. Meteorol. Soc. 1976, 102, 313-333. [CrossRef]

5. Meyer, M.B.; Lala, G.G. FOG-82 : A cooperative field study of radiation fog. Bull. Am. Meteorol. Soc. 1986, 65, 825-832. [CrossRef]

6. Guedalia, D.; Bergot, T. Numerical forecasting of radiation fog. Part II: A comparison of model simulations with several observed fog events. Mon. Weather Rev. 1994, 122, 1231-1246. [CrossRef]

7. Duynkerke, P.G. Turbulence, radiation and fog in Dutch stable boundary layers. Bound. Layer Meteorol. 1999, 90, 447-477. [CrossRef]

8. Fuzzi, S.; Laj, P.; Ricci, L.; Orsi, G.; Heintzenberg, J.; Wendisch, M.; Yuskiewicz, B.; Mertes, S.; Orsini, D.; Schwanz, M.; et al. Overview of the Po Valley experiment 1994 (CHEMDROP). Contr. Atmos. Phys. 1998, 71, 3-19.

9. Haeffelin, M.; Bergot, T.; Elias, T.; Tardif, R.; Carrer, D.; Chazette, P.; Colomb, M.; Drobinski, P.; Dupont, E.; Dupont, J.C.; et al. PARISFOG : Shedding new light on fog physical processes. Bull. Am. Meteorol. Soc. 2000, 91, 767-783. [CrossRef]

10. Pu, X.; Chachere, C.N.; Hoch, S.W.; Pardyjak, E.; Gultepe, I. Numerical prediction of cold season fog events over complex terrain: The performance of the WRF model during MATERHORN fog and early evaluation. Pure Appl. Geophys. 2016, 173, 3165-3186. [CrossRef]

11. Bergot, T.; Terradellas, E.; Cuxart, J.; Mira, A.; Liechti, O.; Mueller, M.; Nielsen, N.W. Intercomparison of single-column numerical model for the prediction of radiation fog. J. Appl. Meteorol. Climatol. 2007, 46, 504-521. [CrossRef]

12. Terradellas, E.; Bergot, T. Comparison between two single-column models designed for short-term fog and low-clouds forecasting. Fisica Terra 2007, 19, 189-203.

13. Roman-Cascon, C.; Steeneveld, G.Y.; Yague, C.; Sastre, M.; Arrillaga, J.A.; Maqueda, G. Forecasting radiation fog at climatologically contrasting sites: evaluation of statistical methods and WRF. Quart. J. R. Meteorol. Soc. 2016, 142, 1048-1063. [CrossRef]

14. Steeneveld, G.Y.; De Bode, M. Unravelling the relative roles of physical processes in modelling the life cycle of a warm radiation fog. Q. J. R. Meteorol. Soc. 2018, 144, 1539-1554. [CrossRef]

15. Maronga, B.; Bosveld, F.C. Key parameters for the life cycle of nocturnal radiation fog: a comprehensive large-eddy simulation study. Q. J. R. Meteorol. Soc. 2017, 143, 2463-2480. [CrossRef]

16. Gultepe, I.; Mueller, M.D.; Boybeyi, Z. A new warm fog parameterization scheme for numerical weather prediction models. J. Appl. Meteorol. 2006, 45, 1469-1480. [CrossRef]

17. Tardif, R.; Rasmussen, R.M. Event-based climatology and typology of fog in New-York city region. J. Appl. Meteorol. Climatol. 2007, 46, 1141-1168. [CrossRef] 
18. Cuxart, J.; Jimenez, M.A. Deep radiation fog in a wide closed valley: study by numerical modeling and remote sensing. Pure Appl. Geophys. 2012, 169, 911-926. [CrossRef]

19. Bergot, T. Small-scale structure of radiation fog: A large-eddy simulation study. Q. J. R. Meteorol. Soc. 2013, 139, 1099-1112. [CrossRef]

20. Bari, D.; Bergot, T.; El Khlifi, M. Numerical study of a coastal fog event over Casablanca-Morocco. Q. J. R. Meteorol. Soc. 2015. 141, 1894-1905. [CrossRef]

21. Sandu, I.; Brenguier, J.L.; Geoffroy, O.; Thouron, O.; Masson, V. Aerosol impacts on the diurnal cycle of marine stratocumulus. J. Atmos. Sci. 2008, 65, 2705-2718. [CrossRef]

22. Bougeault, P.; Lacarrere, P. Parameterization of orography-induced turbulence in a mesobeta-scale model. Mon. Weather Rev. 1989, 117, 1872-1890. [CrossRef]

23. Cuxart, J.; Bougeault, P.; Redelsperger, J.L. A turbulence scheme allowing for mesoscale and large-eddy simulations. Quart. J. R. Meteorol. Soc. 2000, 126, 1-30. [CrossRef]

24. Deardorff, J. Stratocumulus-capped mixed layers derived from a three dimensional model. Bound. Layer Meteorol. 1998, 18, 495-52. [CrossRef]

25. Noilhan, J.; Planton, S. A simple parameterization of land surface processes for meteorological models. Mon. Weather Rev. 1989, 117, 536-549.

[CrossRef]

26. Pinty, J.P.; Jabouille, P. A mixed-phase cloud parameterization for use in mesoscale non hydrostatic model: Simulations of a squall line and of orographic precipitations. In Proceedings of the Conference on Clouds Physics, American Meteor Society, Everett, WA, USA, August 1998; pp. 217-220.

27. Mlawer, E.J.; Taubman, S.J.; Brown, P.D.; Iacono, M.J.; Clough, S.A. Radiative transfer for inhomogeneous atmospheres: RRTM a validated correlated-k model for the longwave. J. Geophys. Res. 1997, 102, 16663-16682. [CrossRef]

28. Morcrette, J.J. Radiation and cloud radiative properties in the European Centre for Medium Range Weather Forecasts forecastinf systeme. J. Geophys. Res. 1991, 96, 9121-9132.

[CrossRef]

29. Price, J.D. Radiation fog. Part I: Observations of stability and drop size distributions Bound. Layer Meteorol. 2011, 139, 167-191.

30. Roquelaure, S.; Bergot, T. Contributions from a Local Ensemble Prediction System (LEPS) for improving fog and low cloud forecasts at airports. Wea. Forecast. 2009, 24, 39-52. [CrossRef]

(C) 2019 by the authors. Licensee MDPI, Basel, Switzerland. This article is an open access article distributed under the terms and conditions of the Creative Commons Attribution (CC BY) license (http:/ / creativecommons.org/licenses/by/4.0/). 